\title{
Comments/Rebuttals
}

\section{Rebuttal: Disturbance to Surface Lithic Components of Archaeological Sites by Drill Seeding}

\author{
Jeffrey A. Rust ${ }^{1}$ and Dale Earl ${ }^{2}$ \\ Authors are ${ }^{1}$ Registered Professional Archaeologist, 355 N Vernal Ave, Vernal, UT 84078, USA; and ${ }^{2}$ Archaeologist, Bureau of Land Management, \\ Salt Lake Field Office, 2370 S 2300 W, Salt Lake City, UT 84119, USA.
}

In March 2011, Rangeland Ecology \& Management published an article by Neal M. Bryan, Val Jo Anderson, and Rachel A. Fugal entitled "Disturbance to Surface Lithic Components of Archaeological Sites by Drill Seeding” (Bryan et al. 2011). The authors present the argument that archaeological compliance on federal lands can delay the seeding of perennial plants in disturbed areas, thus allowing invasive species to grow. The authors then present an experiment in which a mechanical seed drill was used across an experimental surface lithic scatter to quantify their stance that archaeological sites receive minimal damage from mechanical seed drilling. They finally conclude that "drill seeding may carry less risk to cultural sites than no treatment at all" and that "it may be appropriate and expeditious for agencies to conduct less intense surveys."

We feel that the article has several flaws and that the conclusions are misleading. We have provided the following rebuttal to clarify some of the archaeological issues.

\section{The Experiment: Drill Seeding an Experimental Lithic Scatter} The authors conducted an experiment to measure the movement and effects of a rangeland drill on replica lithic flakes and lithic tools within an experimental surface lithic scatter. We assert that an experiment and a discussion that studies the potential damage to archaeological sites needs to address what makes an archaeological site important and what type of damage could adversely affect the integrity of the site. It is important to understand that not all archaeological sites are the same and not all archaeological sites have the same ability to meet National Register significance. In fact, under federal regulations, agencies typically do not protect archaeological sites that do not meet National Register Criteria. A surface lithic scatter, similar to the one created by the authors, typically would not meet National Register criteria and would not have been avoided during a reseeding project. The experiment is flawed because it attempts to test the effects of drill seeding on a site that does not contain any of the archaeological characteristics that would warrant avoidance in the first place.

The authors have used the data from their experiment to assert that drill seeding poses only "negligible risk to archaeological sites characterized by surface lithic scatters." In contrast to the claims of the article, we assert that the data from the experiment confirms that drill seeding damages artifacts, moves archaeological materials across the site, and stirs up or buries materials to the depth of the drill or disk. Although we do not dispute the results that drill seeding had on

Correspondence: Jeffrey R. Rust, 355 N Vernal Ave, Vernal, UT 84078, USA. Email: jeffreyarust@ yahoo.com

Manuscript received 28 June 2011; manuscript accepted 5 July 2011. the author's experimental surface lithic scatter, we do dispute how the results of the experiment could apply to other types of cultural sites. The movement and breakage of artifacts demonstrated by their experiment most likely would damage the archaeological record of a National Register-eligible site.

In their defense, Bryan et al. (2011) carefully have worded much of their article to ensure that their analysis is only indicative of impacts to "surface lithic scatters" or "surface lithic components of archaeological sites." The authors use the data from the experiment to show that drill seeding poses "negligible risk to archaeological sites characterized by surface lithic scatters." However, they also make broader statements such as "drill seeding may carry less risk to cultural sites than no treatment at all." The shift between discussing effects to "surface lithic scatters" and risk to "cultural sites" in general is disconcerting, because their experiment does not address other components of archaeological sites.

Bryan et al. (2011) provided statistics on the results of the experiment, but we are concerned that they did not provide quantitative data about the makeup of their sample. For instance, although they state that their sample was made of chert, quartzite, and obsidian, they fail to specify the quantities of each material, quantities of lithic flakes, or quantities of lithic tools. By omitting such vital information about the makeup of their own sample, the authors make it virtually impossible to recreate their experimental conditions in future tests of this hypothesis. The lack of information on their sample also makes it impossible to determine if their results are as statistically significant as they claim. Although Bryan et al. (2011) do furnish the reader with $P$ values that at first glance might seem statistically significant, their lack of raw data means that the reader cannot reproduce any of their calculations. This leaves the reader in the position of simply trusting the authors and ignoring the possibility of errors in their calculations, or rejecting their conclusions out of hand for lack of reproducible results.

One of the final flaws in their experiment was the decision not to consider artifact size as an experimental factor in their study. Much of the archaeological literature on tillage effects on archaeological sites indicates that artifact size can have an enormous impact on the manner in which artifacts are moved by plowing (see for example, Lewarch and O'Brien 1981; Odell and Cowan 1987; Dunnell and Simek 1995).

\section{Adverse Effects to Subsurface Cultural Materials}

The value and significance of archaeological sites under the requirements of the National Historic Preservation Act relate to the ability of a site to provide important information about the history or prehistory of the region. A site's ability to provide significant information is dependent on a variety of components. 
Prehistoric sites in particular have great potential to provide significant information about cultural periods about which we know very little. Much of the information required to answer questions about prehistory potentially is found in the intact buried remains of cultural sites. Significant sites could contain charcoal, plant pollens, faunal materials, floral materials, and artifacts that have remained buried in a relatively stable context for thousands of years. Because archaeological data is so reliant on context (spatial relationships between artifacts and archaeological materials), it is essential to keep sites as intact as possible until the data can be recovered. In some cases, the movement of an artifact by a few centimeters can be the difference between tying it to a specific cultural period and losing its archaeological context. Because cultural remains often are fragile due to age, erosion, deterioration, and modern disturbances, the remaining materials can be damaged or destroyed by relatively minor impacts. Although federal agencies are not responsible for damage to cultural resource from natural erosion and deterioration, they are responsible for potential damage to cultural resources caused by federal undertakings or activities.

Bryan et al. (2011) state that archaeological sites have been "exposed to the forces of wind, water, soil, ice, salt, gravity, seismic activity, animals, plants, and human pedoturbation" for thousands of years and because of these factors, "surface or subsurface artifacts cannot be assumed to have originated where they are found." While we agree that archaeological sites are affected by environmental forces, we do not agree that artifacts cannot be assumed to have originated where they are found. Standard archaeological practices stress that surface and subsurface artifacts should be assumed to be in their original context until the geomorphology, cultural strata, and site analysis indicate otherwise. Archaeological analysis of a site includes an evaluation of the depositional, erosional, and environmental processes of the site area in order to understand the integrity of a site. Even though some sites have been affected heavily by environmental forces, thousands of archaeological excavations across the intermountain west have demonstrated that a large percentage of sites have intact features and stratigraphy, regardless of the perceived environmental degradation. Subsequently, archaeologists assume that all sites contain significant data, until they are evaluated for National Register significance and are proven otherwise. Federal policy requires us to do so.

Because the authors focused exclusively on the movement and breakage of surface lithics, they did not address how drill seeding could stir up intact subsurface materials or introduce contaminants into buried components of the site. Even though the language of the article intended to portray drill seeding as a minimally invasive activity, the results of the experiment clearly confirm that drill seeding can disturb archaeological materials to a depth of the drill and move artifacts and cultural materials up to $100 \mathrm{~cm}$ away from their original location. Such activity clearly has the potential to adversely affect National Registereligible archaeological sites.

\section{The Archaeological Literature}

We are concerned that Bryan et al. (2011) have misinterpreted the archaeological literature they have referenced in their study. For instance, the authors refer to Horobik and Parkisons (2007) for their argument that surface collections are not necessarily representative of subsurface collections. In reality,
Horobik and Parkisons (2007) is a student paper that attempts to analyze how surface artifacts relate to subsurface features at a Copper Age site in Hungary. The article indicates that surface artifacts on the site had been heavily disturbed through years of plowing and the authors conclude that in such cases the surface artifacts have moved and are no longer directly positioned over their original location. A careful reading of Horobik and Parkisons (2007) shows that plowing activities are far from an innocuous activity and are one way in which the information from the archaeological record can be severely damaged.

We also feel that the authors have misinterpreted lithic studies such as Nance and Ball (1981) and Lewarch and O'Brien (1981). Bryan et al. (2011) assert that the displacement of artifacts in their experiment is "not likely to affect the results of most studies" because the movement of artifacts is within the scale of analysis. The focus of Nance and Ball's 1981 article was that archaeologists should use smaller grid sizes in data collection, specifically because prior studies had not used an adequate scale of analysis. Lewarch and O'Brien (1981) use proportional weight algorithms to find ways to gather data from sites that have been damaged through plowing. Their article should not be construed to recommend that archaeological sites can simply be plowed over because sufficient data can be gathered after the damage is done. To the contrary, Lewarch and O'Brien's (1981) paper should make it clear that plowing does result in an actual loss of archaeological data and seriously hampers archaeological research.

\section{Misunderstanding "Lithic Scatters"}

We believe that Bryan et al. (2011) have misunderstood the significance of archaeological sites labeled as "lithic scatters." Outside of the archaeological discipline, there is a general misperception that sites labeled as "lithic scatters" solely are comprised of a surface scattering of lithic flakes. Archaeologists often use the term "lithic scatter" as an initial catch-all term during documentation for sites that contain lithic debris. Because the initial review and documentation is often very brief and cursory, further evaluation and testing of sites labeled as "lithic scatters" often finds that the sites contain subsurface features, artifacts, or cultural materials that were not initially visible on the surface of the ground. The use of "lithic scatter" as a type site is ubiquitous to archaeology because lithic materials typically are the most durable artifacts on a site. As archaeological sites erode over time, many exposed materials and artifacts on the surface of the ground decompose, but lithic materials endure. Surface lithic scatters often serve as indicators of more substantial buried cultural deposits that still contain artifacts or materials that can provide valuable information about the prehistory of the region.

\section{Archaeological Survey vs. Archaeological Avoidance}

The authors state that because their mechanical drill seed test showed minimal effects to experimental lithic scatters, then future "drill seeding could proceed with less-intensive archaeological surveys." The determination that one type of activity might minimally affect one type of site should not lead to an assumption that archaeological surveys can or should be reduced.

Federal regulations state that "identification efforts" must always be a "reasonable and good faith effort" to "identify 
historic properties within the area of potential effects" (36 CFR $800.4[\mathrm{~b}])$. The Secretary of the Interior's Standards and Guidelines provide guidance for federal agencies to determine the appropriate level of identification efforts and the appropriate level of documentation. Because federal agencies manage a wide variety and complexity of cultural resources, they have broad discretion to determine how they define a "reasonable and good faith effort." This discretion is tempered by the requirement to use qualified cultural resource professionals who meet the Secretary of the Interior's professional qualification standards (36 CFR 800.2[a][1] and 36 CFR 61) to complete the identification efforts. In the western United States, typical identification efforts include archaeological pedestrian survey with archaeologists walking transects (spaced 15 to $30 \mathrm{~m}$ apart) across the landscape. This type of archaeological survey is a systematic review of sites across the landscape and typically is considered sufficient to meet most identification effort requirements under the law.

The sites found during the survey are documented and evaluated for National Register eligibility. The agency reviews the proposed activities of the project and determines how the project will affect the National Register-eligible sites. If the project has the potential to adversely affect National Registereligible sites, then the agency must come up with ways to avoid, minimize, or mitigate those effects (36 CFR 800.6[a]) and must consult with the State Historic Preservation Officer. Many agencies opt to avoid National Register-eligible sites because it is initially cheaper, quicker, and easier than coming up with other solutions. As Bryan et al. (2011) clearly have indicated in their article, simple avoidance does not always produce the desired results. In many range-seeding projects, the agency may have better success to review other seeding options that would not adversely affect the sites, rather than simply avoiding the sites and leaving them without protective vegetation.

\section{Rangeland Seeding Options and Archaeological Site Avoidance}

The article assumes that mechanical treatments, such as drill seeding, are the only feasible method for planting perennial seeds and that avoidance of an archaeological site is the only option for complying with cultural resource regulations.

Bryan et al. (2011) cite various sources to confirm that that effective and timely revegetation of disturbed sites is essential to curbing annual weed invasion and that the rangeland seed drill is the preferred method for the revegetation process because of the cost and the ability to put the seeds in intimate contact with the soil. Although we do not dispute either of these statements, we present the idea that there are other effective seeding options that could be used on archaeological sites, such as hydro seeding, matt seeding, or mulch seeding, that also put the seeds in intimate contact with the soil but that do not have the ground-disturbing impact of drill seeding. Because alternate seeding options are more expensive and require more labor, they were not discussed in the article.

In the beginning of the article, the authors call for "informed decisions balancing archaeological values with rangeland health." We agree and we assert that the concept of balancing archaeological values with rangeland health requires discussing alternate solutions for both resources. The authors have discussed alternate solutions for archaeological practices but have not discussed alternate solutions for rangeland practices that could avoid impacts to cultural resources. Cultural resource compliance does not result automatically in mandated avoidance of all archaeological sites, but it does require an agency to evaluate all potential options and then weigh the options in light of historic preservation. Options usually are available which can both protect cultural sites and provide for effective range health. We recommend that archaeologists and range specialists discuss a variety of options that meet range objectives and protect archaeological sites. Previous conversations typically have consisted of archaeologists stating that drill seeding will damage archaeological sites and range specialists responding with concerns that avoidance will be detrimental to range health. The conversations need to get past stating the concerns and getting to an acceptable solution for both resources. Then the discussion can begin to weigh the costs of various treatments with the effects to archaeological sites and range health. The discussion should go beyond what is the least expensive or quickest and focus on what is most effective and beneficial for both resources in the long term, taking into account legal requirements for both resources.

\section{IMPLICATIONS}

The Section 106 process (36 CFR 800) is often perceived negatively because range specialists feel that "pending archaeological clearance can result in the postponement or exclusion of effective seeding practices." In reality, the laws to protect cultural resources are an important part of a federal agency's mission and do not necessarily have to be a barrier to effective range health. The National Historic Preservation Act and related federal regulations provide agencies with broad methods to protect archaeological sites and to streamline project compliance. Agencies can take proactive steps to develop protocols or agreements with the State Historic Preservation Officer on essential range treatments prior to the occurrence of critical circumstances that necessitate emergency treatments. These agreements could consider the potential effects of various treatments on cultural resources and determine what types of activities can be expeditiously authorized. The agreements can be a way to streamline the review process so that solutions are ready before the emergency occurs. Ultimately, range improvements can be successfully managed, while still protecting cultural resource sites if professionals from both disciplines will discuss the issues of each discipline and consider the broad spectrum of solutions.

\section{LITERATURE CITED}

Bryan, N. M., V. J. Anderson, and R. A. Fugal. 2011. Disturbance to surface lithic components of archaeological sites by drill seeding. Rangeland Ecology \& Management 64(2):171-177.

Dunnell, R. C., And J. F. Simek. 1995. Artifact size and plowzone processes. Journal of Field Archaeology 22(3):305-319.

HoroBIK, H., AND W. PARKISONS. 2007. Exploring the reliability of archaeological site survey through the GIS based analysis of surface artifact distribution at Körösladány 14. Journal of Young Investigators: An Undergraduate, Peer- 
Reviewed Science Journal 16(6). Available at: http://www.jyi.org/research/re. php?id=1086. Accessed 11 April 2011.

LewARCH, D. E., AND M. J. O'Brien. 1981. Effect of short term tillage on aggregate provenience surface pattern. In: M. J. O'Brien and D. E. Lewarch [EDS.]. Plowzone archeology: contributions to theory and technique. Publications in Anthropology No. 27. Nashville, TN, USA: Vanderbilt University. p. 7-49.
Nance, J. D., And B. F. Ball. 1981. The influence of sampling unit size on statistical estimates in archeological site sampling. In: M. J. O'Brien and D. E. Lewarch [EDS.]. Plowzone archeology: contributions to theory and technique. Publications in Anthropology No. 27. Nashville, TN, USA: Vanderbilt University. p. 51-69.

OdelL, G. H., AND F. Cowen. 1987. Estimating tillage effects on artifact distribution. American Antiquity 52(3):456-484. 